\title{
Bibliometric Analysis on the Research Hotspot and Frontiers of Higher Engineering Education-Taking the Research Publications on Higher Engineering Education from 2011 to 2020 as the Sample
}

\author{
Lei $\mathrm{Li}^{1}$, Shining $\mathrm{Gao}^{2}$, Pingping Deng ${ }^{2}$ and Haiying $\mathrm{Ma}^{3, *}$ \\ ${ }^{1}$ School of Materials Science and Engineering, Harbin Institute of Technology, Weihai, Shandong 264209, China \\ ${ }^{2}$ School of Economics and Management, Harbin Institute of Technology, Weihai, Shandong 264209, China \\ ${ }^{3}$ Student Affairs Office, Harbin Institute of Technology, Weihai, Shandong 264209, China \\ *Corresponding author. Email: mahaiying@hitwh.edu.cn
}

\begin{abstract}
In order to further investigate the development process of higher engineering education, sort out and summarize the research status and cutting-edge perspectives, this work presented a bibliometric analysis on the 1830 published papers from 2011 to 2020 on the journal Research in Higher Education of Engineering (in Chinese) using CiteSpace software. The main outputs of this work lie in the knowledge maps including the author cooperation network, institutional cooperation network, theme word co-occurrence network, emergent analysis, etc. The results showed that 1) the authors have close cooperation and exchanges, and have formed a "leader + backbone" research team, and 2) the cooperation between institutions is relatively extensive but the cooperation between institutions need to be further strengthened. In the engineering education and higher engineering education, there are many hot topics that have been generated. In this context, to identify the biggest emerging keywords of new engineering is of contribution to understanding the most important hot and frontier topics in the field of higher engineering education in the future.

Keywords: higher engineering education, emerging engineering, knowledge map, CiteSpace

\section{INTRODUCTION}

Since the 18th CPC National Congress, the CPC Central Committee has attached great importance to major scientific and technological innovation and engineering scientific and technological talents. The General Secretary $\mathrm{Xi}$ Jinping has pointed out that "major scientific and technological innovations are an important national and powerful weapon, which must be firmly in our own hands and rely on self-reliance and independent innovation." and "The team of engineering scientific and technological talents is the most valuable resource for China to create the future." At present, the scale of higher engineering education in China continues to expand, and the reform of engineering education has been accelerated, thus creating the world's largest engineering education system. The research of higher engineering education is also getting

which mainly presents the current situation before 2016 . Over the last decade, especially after joining the international engineering education "the Washington agreement" in June 2016, the Ministry of Education of China (MEC) made significant efforts to actively promote the construction of new engineering. In September 2018, the MEC and other departments issued the Opinions on Accelerating the Construction and Development of New Engineering Plan for Excellent Engineer Education and Development 2.0, which stands for that China's higher engineering education has entered a critical period of reform and internationalization. Also there have been made many efforts to explore a Chinese model and experience leading global engineering education, and all reform practices and theoretical research have been substantially improved. In this context, it is necessary to analyze and study the current situation of higher engineering education research again.
\end{abstract} attentions by experts, scholars, professional teachers and teaching managers, thus increasing the relevant research results.

It is the basis and premise of deepening the higher engineering education research to sort out and summarize the current research hotspot and frontier, and to further deepen the research on higher engineering education. The existing literature mainly analyzes the current situation and hot frontier of higher engineering education research,

\section{RESEARCH METHODS AND DATA SOURCES}

\subsection{Sample Selection}

This work chose the 2011-2020 published papers on the journal Research in Higher Education of Engineering as 
the research samples, because it is the only national authoritative academic journal for engineering education research in China, sponsored by Huazhong University of Science and Technology and other units. This Research in Higher Education of Engineering is the national Chinese core journal and CSSCI source journal, which can comprehensively and deeply reflect the development process and research results of higher education, especially higher engineering education in China.

\subsection{Research Method}

From the perspective of bibliography, this work analyzed the relevant literature in the field of higher engineering education research in China using CiteSpace software to present a comprehensive use of word frequency statistics, knowledge graph analysis combined with the secondary study of key literature. This work is useful to explore the research output, hot topics and dynamic frontier more comprehensively and objectively.

\subsection{Data Source and Processing}

This article selects the CSSCI database as the data source. The specific collection method includes taking the Research in Higher Education of Engineering as the "source journal", from 2011 to 2020 (excluding supplements non-academic papers such as meeting reviews and character interviews), this work obtained a total of 1,830 eligible papers. The above paper questions were downloaded from the database, and the data was converted into a format available to the software with the data conversion function brought by the CiteSpace software.

\section{CURRENT STATUS OF HIGHER ENGINEERING EDUCATION}

\subsection{Publication Situation Analysis}

The age represents the variation of scientific knowledge. The publications on the Research in Higher Education of Engineering over the 10 years from 2011 to 2020 is shown in Figure 1. As can be seen, the load volume increased from 2011 to 2016, and shows a downward trend from 2017 to 2020. However, the overall number of papers published per year is relatively stable, basically maintained at about 185 per year. This shows that on the one hand, the journal is relatively mature with strict quality, consistent with Tong Rui's research [1]. On the other hand, scholars still maintain high enthusiasm for the field of higher engineering education with rich related research results.

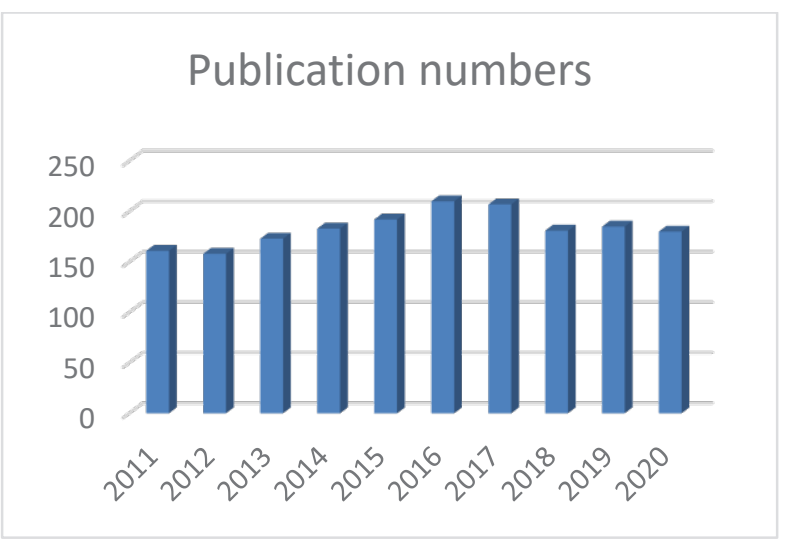

Figure 1. Publication numbers of the Research in Higher Education of Engineering from 2011 to 2020

\subsection{Core Author Analysis}

The number of publications is one measure of a scholar's activity in a certain research field. According to the results of CiteSpace operation, 2,759 people authorized the 1,830 sample documents, among which 35 publications are from Zou Xiaodong from Zhejiang University, followed by 33 publications from Lin Jian from Tsinghua University. The authors who published five papers according to Price's Law can be considered the core authors in the field. As such, 105 core authors were identified with a total of 893 articles.

From the perspective of cooperative relations, scholars have relatively close cooperation and exchanges, and a relatively large cooperation network has been formed as shown in Figure 2. Many scholars have been deeply engaged in the research field for years, and have a relatively stable and strong research team. For example, Professor Lin Jian of Tsinghua University, who served as the principal of Wuyi University, has been engaged in economic and management research of higher education for a long time, with many research achievements in the aspects of excellent engineer education training, new engineering construction and international comparison of higher engineering education. Most of Professor Lin Jian's papers were completed independently, and he co-authored only 13 papers, accounting for about $1 / 3$ with cooperation with Xuzhidan and Peng Lin. Zou Xiaodong, deputy Secretary of the Working Committee of Central and State Organs, served as the Secretary of the Party Committee of Zhejiang University. He has been engaged in higher education and technology management strategy and policy research for a long time, and has achieved fruitful research results in the theory and policies of higher education, higher education, higher engineering education and university governance. Relying on the China Institute of Science and Education Development Strategy of Zhejiang University, a research team has been formed, with Zou Xiaodong as the core and Zhu Ling, Zhang Wei, Yao Wei and $\mathrm{Wu}$ Wei as the main representatives. Professor Wang Sunyu, director of the Academic Committee of the 
Institute of Education and deputy editor of the Research in Higher Education of Engineering of Tsinghua University, has devoted himself to studying engineering education for decades. He is familiar with the history of engineering education and has cooperated most with Zeng Kaifu.

Of course, we also found a group of scholars who may not be involved in the field of higher engineering education for a long time, but fruitful publications are presented. For example, Zhang Wei, a researcher from Zhejiang University, published 17 articles in this journal from 2016 to 2020, and $\mathrm{Lu}$ Guodong of Zhejiang University published 18 articles in this journal from 2014 to 2020, showing a strong explosive power.

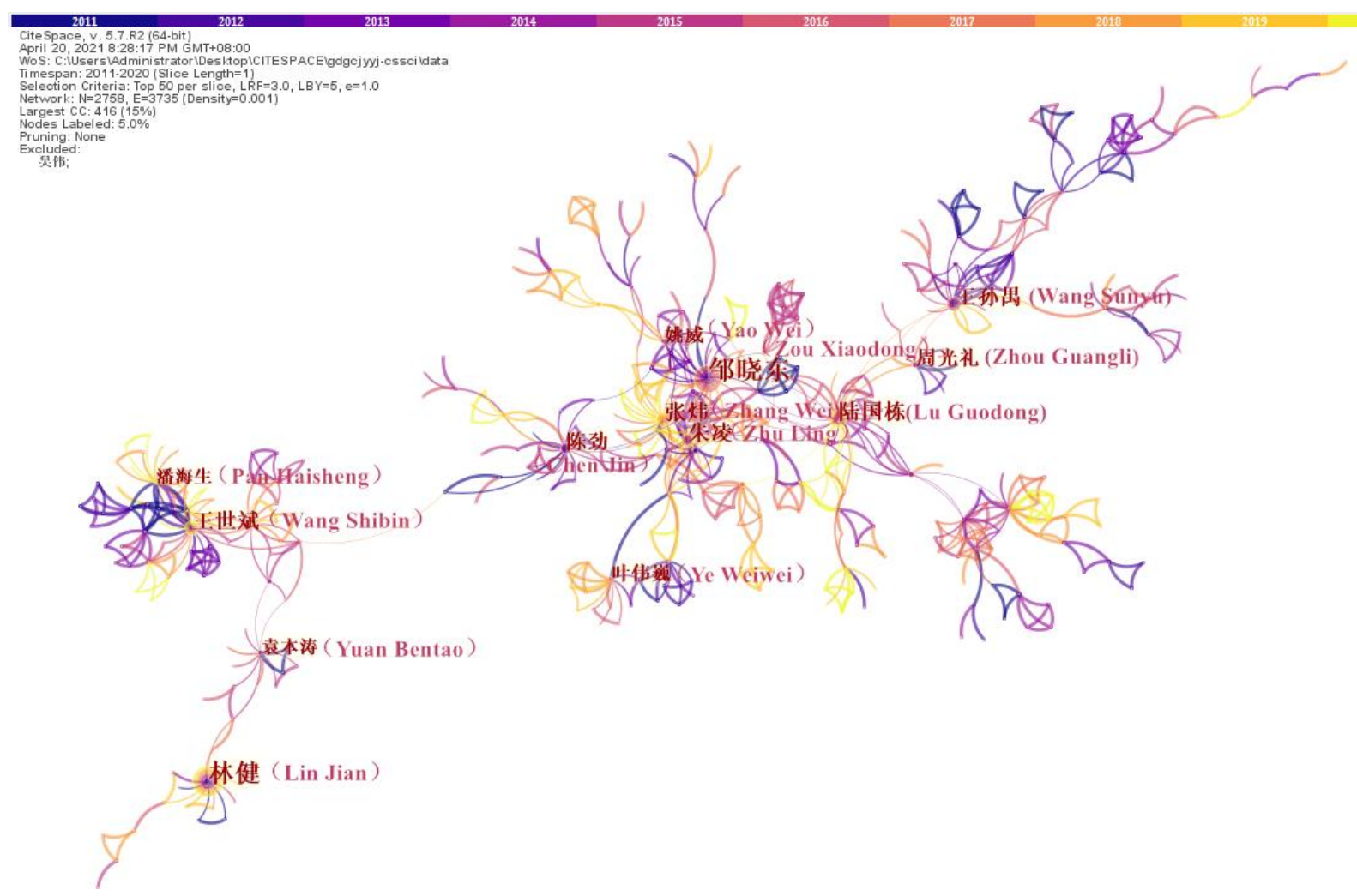

Figure 2. Author cooperative networks

\subsection{Analysis of the Major Research Institutions}

According to the results of CiteSpace operation, Zhejiang University published the most papers with a total of 212 articles. According to Price's Law, the institutions that published more than 11 papers can be identified as core institutions with a total number of 45 . Inter-institutional cooperation is not as close as cooperation between authors (as shown in Figure 3), but it also forms a certain network of cooperation. The Chinese Academy of Engineering, Huazhong University of Science and Technology, Harbin Institute of Technology, South China University of Technology have carried out extensive cooperation. South China University of Technology also has more secondary institutional cooperation. Cooperation between institutions still needs to be further strengthened. 


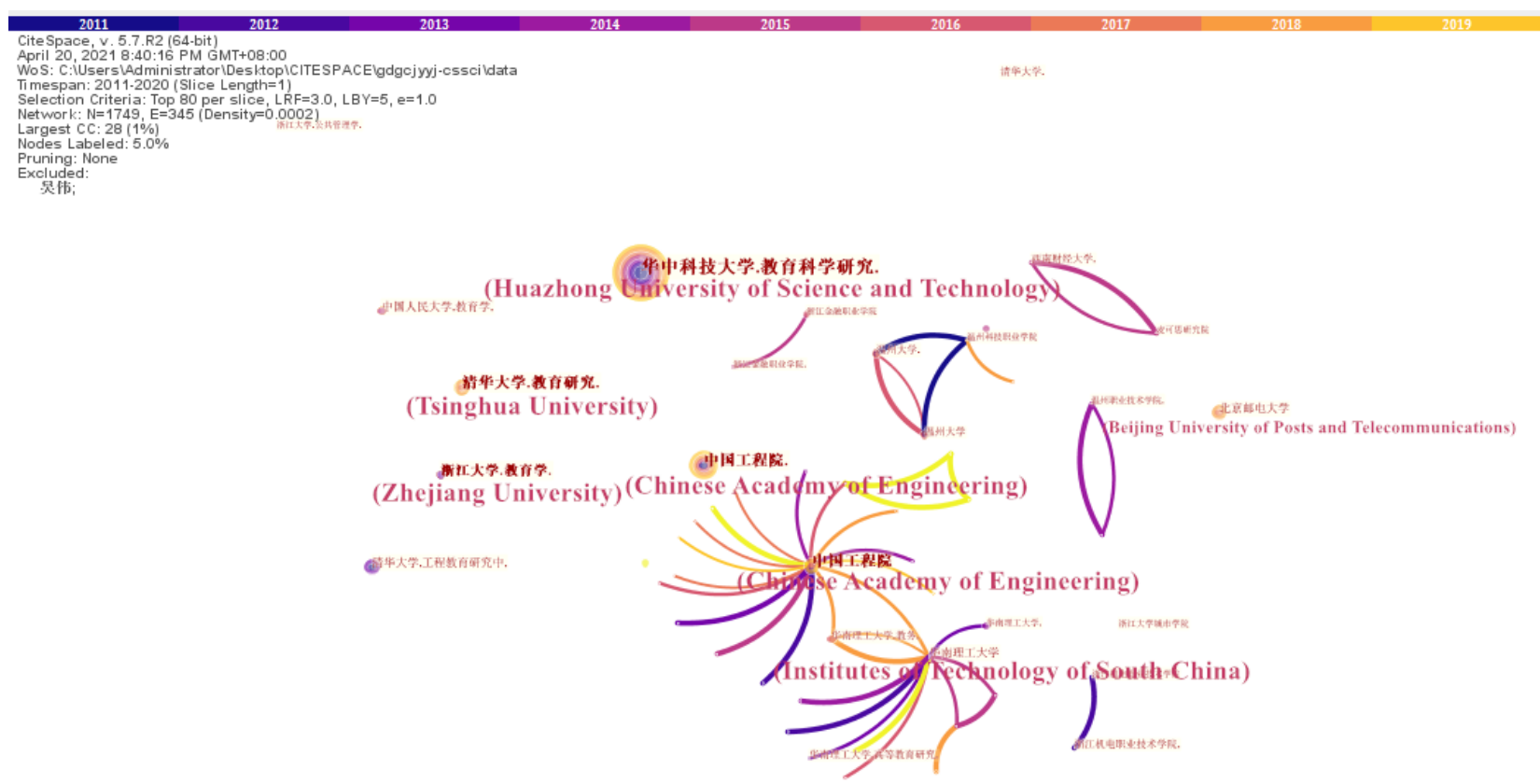

Figure 3. Institutional cooperative network atlas

The top 20 research institutions (see Table 1) were selected for further research. In addition to the Chinese Academy of Engineering, the 19 examples are all universities, which shows that universities are the main institutions of higher engineering education research. Most of the 19 universities are in the types of science and technology. In addition to Wenzhou University, Zhejiang University of Technology, Zhejiang University City College and Shantou University, the other 15 universities are under the key construction universities of the national "Double First-class", "Project 985" and "Project 211". It can be seen that the higher engineering education research strength is closely related to the school engineering strength. The top five universities in the document are Zhejiang University, Huazhong University of Science and Technology, Tsinghua University, Tianjin University and Beijing University of Aeronautics and Astronautics. The five universities are all good at science and technology, and they are art the top of the USNews 2021 World University Engineering List where Tsinghua University is ranked as the first.

In terms of regional distribution of the 19 universities, 12 in the south, 7 in the north, 16 in the east, 1 in the central region and 2 in the west, which shows that the universities in the eastern region, especially Beijing, Shanghai, Guangdong and Zhejiang, are the main force of higher engineering education research. This consistent with the economic and social development and location distribution of colleges and universities.

Further analyzing the secondary units of universities, the School of Education, Huazhong University of Science and Technology published 108 articles, followed by the Education Institute, Tsinghua University with 87 publications, and School of Education, Tianjin University, and Science and Education Development Strategic Research Center, Zhejiang University with same number of 53 publications. If considering the affiliation and historical evolution of the Development Strategic Research Center, Zhejiang University, there are 106 papers signed by this institute. The School of Education, Huazhong University of Science, Education Institute, Tsinghua University, School of Education, Tianjin University all have doctoral awarding quantification in the educational disciplines. As such, the professional background and discipline advantages have promoted the research of higher engineering education. At the same time, the School of Education, Huazhong University of Science and Technology is also the editorial department of the Research in Higher Education of Engineering.

Table 1. Publication statistics of major research institutions

\begin{tabular}{cccc}
\hline Orders & Institutions & Number of publications & Locations \\
\hline 1 & Zhejiang University & 212 & Zhejiang \\
2 & Huazhong University of Science and Technology & 169 & Hubei \\
3 & Tsinghua University & 121 & Beijing \\
4 & Tianjin University & 73 & Tianjin \\
5 & Beijing University of Aeronautics and Astronautics & 62 & Beijing \\
6 & Institutes of Technology of South China & 61 & Guangdong \\
\hline
\end{tabular}




\begin{tabular}{cccc}
\hline 7 & Shanghai Jiao Tong University & 56 & Shanghai \\
8 & Wenzhou University & 55 & Guangdong \\
9 & Chinese Academy of Engineering & 50 & Beijing \\
Shaanxi \\
10 & Xi'an Jiao Tong University (XJTU) & 46 & Chongqing \\
11 & Chongqing University & 32 & Zhejiang \\
12 & Zhejiang University of Technology & 31 & Zhejiang \\
13 & Wenzhou Medical University & 30 & Shanghai \\
14 & Tongji University & 26 & Beijing \\
15 & Beijing University of Technology & 25 & Zhejiang \\
16 & City College of Zhejiang University & 25 & Liaoning \\
17 & Dalian University of Technology & 25 & Guangdong \\
18 & Shantou University & 23 & Beijing \\
19 & Renmin University of China & 23 & Shanghai \\
20 & East China Normal University & 21 & .Pung
\end{tabular}

\section{RESEARCH HOTSPOT ANALYSIS}

Keywords are the most direct reflection and overview of the theme and content of the publication Through the frequency analysis of key words, we can understand and judge the research topics of relevant disciplines, institutions and journals during a period. Selecting the node Keyword, TopN $=20$ in the CiteSpace, and using the
"Pathfinder path-finding algorithm" and "Pruning cliced networks" to tailor the network connection, the final keyword co-occurrence network can be obtained as shown in Figure 4 ("N=156, E=299, with a network density of $0.0247 ")$. A node represents a key word, and the larger the node, the higher the corresponding keyword word frequency; the connection between the keywords represents the co-occurrence relationship, and the width represents the co-occurrence strength.

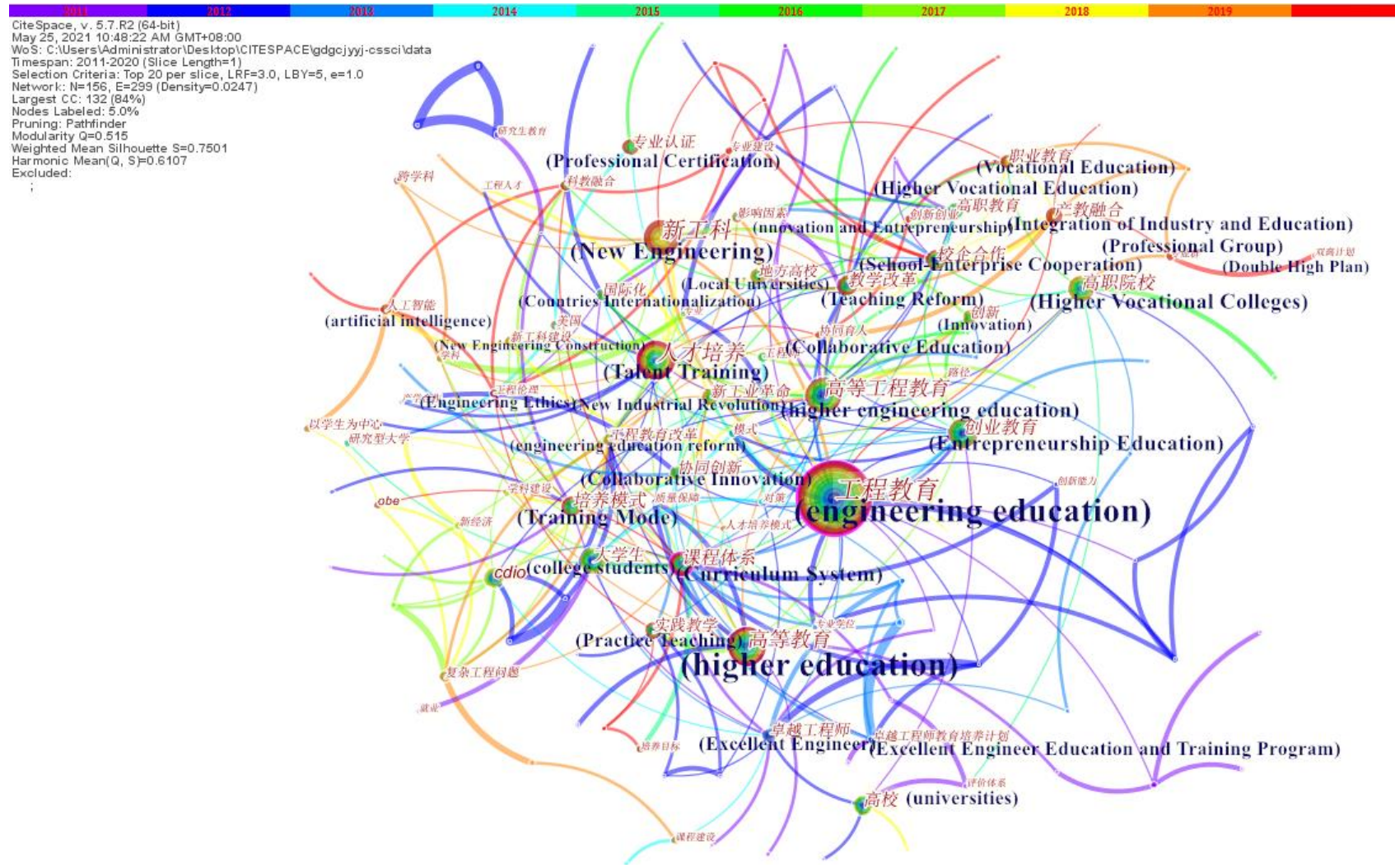

Figure 4. Keyword co-occurrence network

In Figure 4, the largest node engineering education (171), higher education (58), higher engineering education (55), college students (32), universities (26) and other high-frequency keyword frequency reflects that the theme of the Research in Higher Education of Engineering is higher education and higher engineering education, in 
particular. This is also closely related to the orientation of the journal and the characteristics of running the journal. For other high-frequency keywords, we can understand the hotspots of higher engineering education research are mainly as follows: New Engineering (119) and New Engineering Construction (12), Talent Training (76), Entrepreneurship Education (46), Higher Vocational Colleges (38), Training Mode (35), Curriculum System (35), Integration of Industry and Education (29), Teaching Reform (27), School-Enterprise Cooperation (25), CDIO (24), Excellent Engineer (23), and Excellent Engineer Education and Training Program (12), Higher Vocational Education (21), Professional Certification (19), Practice Teaching (19), Collaborative Innovation (18), Vocational Education (17), New Industrial Revolution (17), Innovation (16), Local Universities (16), Countries Internationalization (14), engineering education reform (13), and artificial intelligence (12).

In Figure 4, the Engineering education and curriculum system are nodes with purple outer circle, which represent that the two nodes have high intermediary centrality. This reflects the strong "medium" ability of the nodes in the whole co-occurrence map with more keyword information. Other keywords with intermediary centrality greater than 0.1 are: Higher Engineering Education (0.18), Higher Education (0.15), Entrepreneurship Education (0.15), Excellent Engineer (0.15), Training Model (0.14), and Talent Training (0.11). According to the relationship of keywords in the network, these keywords may become important turning nodes, other keywords around the high-intermediary central keywords, together to express the main content and central idea of the map. The color of the connection changes from cold color to warm color, representing the development of keywords over time. The closer color indicates that the time that keywords produce is fresher. From the figure, many high frequency nodes are linked to the nearest time keywords, suggesting emerging themes over time around the classical theme, such as the New Engineering (2017), Engineering Ethics (2017), Industry and Education integration (2018), artificial intelligence (2018), Innovation and Entrepreneurship (2018), OBE (2018), Collaborative Education (2019), Professional Group (2019), Double High Plan (2020), Big Data (2020), Rain Classroom (2020), etc.

By clustering of the keywords, $Q=0.515$ indicates a significant clustering structure, and $\mathrm{S}=0.7501$ indicates reasonable clustering. A total of 9 clusters are presented, such as \#0 new engineering, \#1 higher education, \#2 outstanding engineer, \#3 integration of industry and education, \#4 higher engineering education, \#5 student-centered, \#6 CDIO, \#7 college students, and \# 8 graduate education, etc. In the past ten years, the research on higher engineering education has been mainly carried out around the above clusters, forming a certain scale. It is pertinent to note that the smaller the serial number, the more keywords that are included.

\section{RESEARCH FRONTIER ANALYSIS}

Research frontier usually refers to the emerging research field or research topics with the most developmental potential for a certain period, and may also be considered as an emergent set of dynamic concepts or potential research problems. CiteSpace software was used to detect keyword protrusion, obtaining 16 keywords for more than 3 years as shown in Figure 5. This reflects the research frontier of different stages in the field of higher engineering education research in China in the past ten years.

Top 16 Keywords with the Strongest Citation Bursts

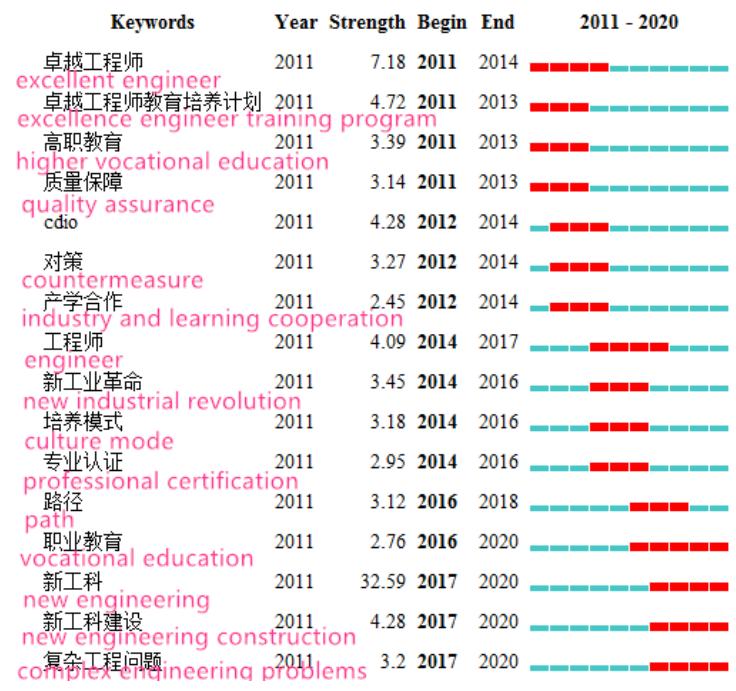

Figure 5. Keyword protrusion map

According to Figure 5, the new engineering is the strongest, followed by outstanding engineers, and the industry and academic cooperation is the least. Vocational education lasted the longest, continuing from 2016 to 2020. Excellent engineer and other 4 keywords appeared the earliest, and new engineering and other 3 keywords appeared the latest. According to the protrusion time, we can roughly divide the frontier of higher engineering education research into three stages.

From 2011-2014, the main key words are: excellent engineer, excellent engineer education and training plan, higher vocational education, quality assurance, CDIO, countermeasures, industry and learning cooperation. The Education and Training Plan for Excellence Engineer is a major reform project for MEC to implement the "Two Outline". Its main purpose is to cultivate many high-quality engineering and technical talents with strong innovation ability and meet the needs of economic and social development. In June 2010, the MEC approved 61 universities, including Tsinghua University and Harbin Institute of Technology, as the first batch of implementation universities, and held a launch meeting at Tianjin University. Colleges and universities have begun to explore the training of excellent engineers, and relevant scholars have also carried out a lot of research. Lin Jian from Tsinghua University has conducted an in-depth study 
on a series of problems including "Excellence Plan" professional training program, teacher team construction, innovation ability training, training characteristic formation, training quality assurance, and proposed countermeasures and suggestions to solve the possible problems, which will provide references for the implementation of "Excellence Plan" in colleges and universities [2-7]. CDIO engineering education mode is a new achievement of international engineering education reform. Shantou University is the leader in implementing CDIO reform. Gu Peihua summarized the promotion and implementation of CDIO in Shantou University and other universities, observed the challenges and existing problems faced by engineering education, and made an outlook for CDIO in China [8-9].

From 2014-2016, the main sudden keywords are: engineers, new industrial revolution, training model, professional certification, path. To cope with the impact of the new industrial revolution on engineering education, Qiu Xueqing and Li Zheng explained the impact of the new industrial revolution of engineering education reform and development, and the countermeasures. They pointed out that the essence of engineering education reform and development is to research and explore the construction of new engineering innovation talent training system [10]. Li Maoguo and Zhu Zhengwei proposed the curriculum system design covering the engineering life cycle, science, culture, engineering technology, information technology, economy, management and law [11].

From 2017-2020, the main key words are: new engineering, new engineering construction, vocational education, complex engineering problems. To actively respond to a new round of scientific and technological revolution and industrial reform, it needs to support a series of national strategies, such as serving innovation-driven development and "Made in China 2025". Since February 2017, MEC has actively promoted the construction of new engineering, and has successively formed the "Fudan Consensus", "Tianda Action" and "Beijing Guide", which constitute the "trilogy" of new engineering construction and explore a new path of engineering education reform. To make clear why to build new engineering, what is new engineering, and how to build new engineering, Zhong Denghua proposed the action plan of "three stages, three tasks and three breakthroughs" [12]. Lu Guodong and Li Tuoyu pointed forward that the construction and development of new engineering must break through five bottlenecks, and should pay attention to the two subjects of teachers and students, focus on cultivating engineering innovation and adapt to change, thus doing a good job of professional certification and identification, integration of online and offline space, coordination of on-campus and off-campus platforms [13]. New engineering education takes talent training as the main line, with teaching, practice, innovation and curriculum as the training methods and means. Comprehensive universities, engineering advantages, and local universities actively practice made beneficial explorations, and put forward implementation plans with their own characteristics. Starting with the goal system, curriculum construction mechanism, interdisciplinary cross-training mode, innovation and entrepreneurship education platform, Sun Yat-sen University has greatly explored the effective ways of the reform of discipline cross-training system to create innovative talents in the new engineering field [14]. Harbin Institute of Technology has systematically promoted the construction of new engineering, and has built a number of new engineering professional groups, and made a new road in engineering education reform, discipline cross-integration, teaching method innovation, and school-enterprise collaborative education and other aspects. It developed and formed the "New Engineering 'Type' Plan of Harbin Institute of Technology", and built an education system and ecological environment for the training of new engineering professionals [15]. Wuhan University of Science and Technology followed the principles of combining crossover and integration, inheritance and innovation, and coordination and sharing, and explored the traditional engineering training mode of innovative talents from three dimensions, such as curriculum system, teaching means and teaching resources [16]. In order to achieve new engineering construction goals, ensure the quality of new engineering talent training, Lin Jian followed the pursuit of "quality excellence, future development, international requirements, macro guidance" principle and developed a set of new engineering talent training quality standards, including discipline professional knowledge, professional quality, complex engineering problem analysis and solutions, engineering responsibility and ethics, communication and team work, engineering leadership, lifelong learning and innovative development, etc. [17].

\section{CONCLUSION}

Based on the publications on the Research in Higher Education of Engineering from 2011 to 2020, this work presented a bibliometric analysis on the annual distribution, author cooperation network, institutional cooperation network, theme word co-occurrence network, sudden occurrence analysis and other knowledge map. This work concludes with the following points.

(1) From the perspective of the development and change process of the annual publications, the load volume increased from 2011 to 2016, and showed a downward trend from 2017 to 2020 . However, the overall number of papers published every year is relatively stable, which reflects that as an authoritative journal in the field of higher engineering education research, the Research in Higher Education of Engineering is relatively mature and publishes articles strictly to ensure the quality of the articles. Of course, while ensuring the quality of the articles, the number of articles should also be increased to give more scholars opportunities to exchange and display.

(2) From the perspective of core author distribution and its cooperation network, 105 authors have published more than 5 journals in the past decade with a total of 893 articles. There are not only the older generation of higher 
engineering educators with experience for many years, but also a large number of new strengths. Scholars have relatively close cooperation and exchanges, and have formed a research team of "leader + backbone".

(3) From the perspective of the distribution of publishing institutions and their cooperation network, universities are the main institutions of higher engineering education research. Science and technology universities built by the state have conducted deep research in this respect, and the number of posts is high. Universities with doctoral points of educational first-level disciplines are especially prominent. There is much cooperation between institutions, while the interinstitutional cooperation needs to be further strengthened.

(4) Based on "high frequency word" and "high intermediary central word" analysis, the general concerns of scholars are: engineering education and higher engineering education, new engineering and new engineering construction, talent training, entrepreneurship education, training mode, curriculum system, integration of industry and education, teaching reform, outstanding engineers, and education and training plan of outstanding engineers. At the same time, around the classic theme, new topics such as ethics, artificial intelligence, OBE, collaborative education and other emerging themes of big data have also emerged with time.

(5) From the emergence analysis of keywords, it is found that the new engineering emergence time is late, but the emergence intensity is the largest, which will be the key field and hot topic of higher engineering education research in the future period.

Overall, the higher engineering education is developing rapidly and in many directions. Colleges and universities should pay close attention to the development direction of higher engineering education, timely discover new problems, explore new ideas to promote the high-quality development of higher engineering education.

\section{ACKNOWLEDGMENT}

This work is one of the research achievements of the Exploration of Talent Training Mode in Universities under the New Engineering Background, supported by the 2021 Student Work Quality Improvement Project of Harbin Polytechnic University, Weihai.

\section{REFERENCES}

[1] Tong Rui. Analysis of Academic Influence of Research in Higher Education of Engineering Quantitative Analysis Based on 2001-2009 CNKI databases[J]. Research in Higher Education of Engineering, 2011, 05: 100-109

[2] Lin Jian. Restudy on the Professional Training Program of "A Plan for Educating and Training
Outstanding Engineers $[\mathrm{J}]$. Research in Higher Education of Engineering, 2011, 04: 10-17+57.

[3] Lin Jian. On the Construction of Teaching Staff Competent for "Outstanding Engineers" Training[J]. Research in Higher Education of Engineering, 2012, 01: $1-14$.

[4] Lin Jian. On Outstanding Engineers' Innovation Ability Training [J]. Research in Higher Education of Engineering, 2012, 05: 1-17.

[5] Lin Jian. Forming Training Characteristics of Outstanding Engineers with Competitive Advantages[J]. Research in Higher Education of Engineering, 2012, 06: 7-21+30.

[6] Lin Jian. Quality Assurance for Outstanding Engineers Training (Part one) [J]. Research in Higher Education of Engineering, 2013, 01: 23-39.

[7] Lin Jian. Quality Assurance for Outstanding Engineers Training (Part two)[J]. Research in Higher Education of Engineering, 2013, 02: 24-40.

[8] Gu Peihua et al. CDIO in China (Part I )[J]. Research in Higher Education of Engineering, 2012, 03 : 24-40.

[9] Gu Peihua et al. CDIO in China (Part two)[J]. Research in Higher Education of Engineering, 2012, 05: 34-45.

[10] Qiu Xueqing et al. The Reform of Engineering Education Oriented to the New Industrial Revolution[J]. Research in Higher Education of Engineering, 2014, 05: $5-14+45$

[11] Li Baoguo, Zhu Zhengwei. Study on the curriculum system for the engineering process[J]. Research in Higher Education of Engineering, 2014, 04: $1-5+14$.

[12] Zhong Denghua. Connotations and Actions for Establishing the Emerging Engineering Education[J]. Research in Higher Education of Engineering, 2017, 03: $1-6$.

[13] Lu Guodong, Li Tuo. Reflections of the Paths of Constructing and Developing Emerging Engineering Education[J]. Research in Higher Education of Engineering, 2017, 03: 20-26.

[14] Chen Hui, Chen Min. On Thoughts and Explorations of Training Emerging Engineering Talents in Comprehensive Universities[J]. Research in Higher Education of Engineering, 2017, 02: 19-23+47. 
[15] Xu Xiaofei et al. Exploration of Emerging Engineering Education and the Cultivation of Innovative Talents[J]. Research in Higher Education of Engineering, 2020, 02: 18-24.

[16] Sheng Jianlong et al. A Preliminary Study on the Reform of Training Modes for Innovative Talents in Mining Engineering Major Based on Emerging
Engineering $[\mathrm{J}]$. Research in Higher Education of Engineering, 2018(05)83-87.

[17] Lin Jian. Development of the General Standards for Training Quality of New Engineering Talents[J]. Research in Higher Education of Engineering, 2020 (03)5-16. 